\title{
Marriage Timing over the Generations
}

\author{
Frans van Poppel • Christiaan Monden • \\ Kees Mandemakers
}

Published online: 8 March 2008

(C) Springer Science + Business Media, LLC 2008

\begin{abstract}
Strong relationships have been hypothesized between the timing of marriage and the familial environment of the couple. Sociologists have identified various mechanisms via which the age at marriage in the parental generation might be related to the age at marriage of the children. In our paper we study this relationship for historical populations. We use a dataset consisting of several hundreds of thousands of marriages contracted in three of the 11 Dutch provinces between 1812 and 1922. We identified the generational links between the brides, grooms, their parents, and grandparents. We studied (a) whether there is a relationship between ages at marriage of (grandfathers) fathers and sons, and ages at marriage of (grandmothers) mothers and daughters and (b) whether this relationship might be explained by social class. We find evidence for a clear effect of the family on age at marriage and substantial intergenerational transmission. The impact that the family of origin has on age at entry into marriage can partly be attributed to social class. We also observed positive effects of grandparents' age at marriage on their offspring's age at marriage.
\end{abstract}

Keywords Age at marriage - Intergenerational transmission - Familial effects · Social class $\cdot$ Netherlands $\cdot$ Multilevel models

F. van Poppel $(\triangle)$

Netherlands Interdisciplinary Demographic Institute, P.O. Box 11650, 2502 AR The Hague, The Netherlands

e-mail: poppel@nidi.nl

C. Monden

Department of Social Cultural Sciences, Tilburg University, Room S 181, P.O. Box 90153, 5000 LE Tilburg, The Netherlands

e-mail: C.W.S.Monden@uvt.nl

K. Mandemakers

International Institute of Social History, University of Amsterdam, Cruquiusweg 31, 1019 AT Amsterdam, The Netherlands

e-mail: kma@iisg.nl 
Until the beginning of the twentieth century, late marriage and definitive celibacy played a key role in the European economic-demographic system. Age of entry into, and the number of women remaining definitively out of, marriage acted as equilibrating forces via which the rate of population growth was adapted to economic conditions (Flinn 1981). The age at entry into marriage was also a key factor affecting the family organization and gender relations in European societies. It determined the moment at which women left the labor force, property was transferred across the generations, and residence changed, and it defined spousal relations and the status of women (Mason 1993; Modell et al. 1976). Identifying the mechanisms regulating the ages at which new couples were formed is therefore essential for understanding the demographic regime of Europe in the past and for an insight into the changes in family life over the past centuries.

In the classical sociological theories of modernization, the decreasing significance that individuals attach to the family in which they are born is the driving force behind the transformation of family life, including that of the age at marriage (Goode 1963; Shorter 1977). Couples increasingly deviated from the values, beliefs and attitudes formed in the context of the family of origin for at least three reasons. First, the family lost many of its former socialization functions: as a consequence, parents had fewer opportunities to leave their marks on every aspect of the child's life. Second, as a consequence of the rise of the welfare state, the power of parents to impose their preferences on their offspring has declined. Third, parents' view of their role in the upbringing of their children has changed from an emphasis on discipline to stimulating children to find their own way in life (Ariès 1982).

Although statements about the effect of the shift from a family-based to an individualbased orientation are frequently found in the historical and sociological literature, studies in which the similarity of marriage characteristics over the generations are studied are rare (Alter and Oris 1999; Anderton et al. 1987; Levine 1982). Historical studies are often not of sufficient size to detect similarities in behavior between generations because the usual techniques such as family reconstitutions rarely allow researchers to follow populations over long periods of time, or they are based on genealogies of atypical populations (Murphy and Wang 2002).

Empirical data on time trends in the degree of concordance between parental behavior and the behavior of children are therefore rarely presented. A further problem is that studies of the strength of the process of intergenerational transmission usually apply to one community only. Recent research has shown the importance of the roles macroeconomic factors and cultural characteristics play in determining the size of individual differences in family behaviors. Reher (1998) has suggested that where a deeply rooted cultural view that family and kinship represent an important institution dominates, intergenerational transmission of family behavior is more prominent than in areas characterized by rather weak family ties.

In this paper we study intergenerational transmission of the age at marriage over a period of almost a century, and for three spatial-cultural contexts. We use information on several children per family, on their parents and their grandparents. Studying the similarity among siblings enables us to assess the total impact of the family and the importance of intergenerational transmission. We use information from a large database for three provinces of the Netherlands that has recently become available and that allows us to address this issue in a way hitherto impossible. Our paper mainly has 
a descriptive and exploratory character and examines whether intergenerational transmission occurred and whether it varied over time and space.

\section{Hypotheses on the Role of Intergenerational Transmission in Nineteenth- and Twentieth-Century Society}

The literature on intergenerational transmission of family behavior distinguishes a number of mechanisms that might explain why children adopt the familial behavior of the parental generation: value socialization, social control, transmission as a side effect of other processes that cause similarities between parents and children, and genetic transmission (Axinn and Thornton 1992; Barber 2001; Glass et al. 1986).

Evolutionary biologists interested in revealing the importance of different lifehistory traits in affecting fitness and longevity have frequently observed strong positive correlations between female age at first reproduction and longevity in premodern societies. Various authors have tried to separate the intergenerational correlations in age at first reproduction in genetic effects and non-genetically inherited effects. It is suggested that the selection gradient on age at first reproduction has changed over time as a consequence of changes in environmentally caused variation and cultural transmission of this life-history trait (Kirk et al. 2001; Pettay et al. 2005). Since the age at reproduction in historical populations is to a large degree dependent on the age at marriage (Anderton et al. 1987), the study of the intergenerational transmission of age at marriage offers an opportunity to test the effect of cultural changes.

In historical populations in particular, value socialization, social control, and the indirect effect of social class similarity between parents and children might cause a similarity between the ages at marriage of parents and children. The role of genetic factors is considered less relevant partly because some randomness in the outcomes will result from the fact that a marriage requires two people.

As marriage was a legally and socially defined turning point in people's lives, parents imposed culturally embedded expectations specifying appropriate ages for this transition and age ranges outside of which this transition was considered inappropriate (Hogan and Astone 1986). Couples knew that it was important to stick to these rules. To affect the age at marriage of their children, parents had available a variety of forms of social control, allowing them to protect the family property, business, and honor, including the legal requirements for parental consent, the transmission of property, parental supervision, dowries, and the manipulation of interaction opportunities (Ariès 1982).

A close correspondence between ages at marriage of parents and children could also result from the fact that ages at marriage strongly depended on the social class to which individuals belonged (Wrigley et al. 1997:123-125) and that social class was to a large degree transmitted from the parental to the child's generation.

We hypothesize that the degree to which ages at marriage of the parental and child generation in the Netherlands were correlated changed over time, and varied between regions, social class, and gender.

We assume that the strength of the intergenerational transmission of age at marriage has decreased over the nineteenth and early twentieth centuries. This is in 
contradistinction with the results of studies on the transmission of fertility, which show an increase in the genetic influence on fertility (Kohler et al. 1999; Murphy 1999). Socialization to an ever-increasing degree took place outside the family environment and was delegated to formal institutions. Increasingly the family organized itself in terms of the children and their future, and the parents' chief psychological and material investment consisted in helping the children get ahead (Ariès 1982). A loss of social control of parents over the attitudes and behavior of their children has taken place owing to a rise of individual paid labor, a declining importance of inheritance and employment within family businesses, and the rise of the welfare state.

We expect regional differences in our data because the three provinces varied in the importance that was attached to the family and to paternal authority. Differences in family ideology, family structure, and family relations between, on the one hand, the western and northern part of the Netherlands (the coastal areas) and, on the other hand, the south and east (Wichers 1965) have been related to differences in religious composition. In the Catholic south, solidarity between generations and parental authority was stressed. Parents and the local clergy exercised a much tighter control over adolescents. For these reasons we expect that the transmission of age at marriage over the generations was considerably stronger in the southern Catholic province of Limburg than in the mixed eastern province of Overijssel and in the Protestant province of Zeeland. Another relevant factor is that households in the south and east were larger and of a more complex structure than those in the north and west. Owing to specific inheritance practices (De Haan and Hoppenbrouwers 1994), the parental generation in Overijssel had more possibilities for social control than parents in Zeeland or Limburg. Given these factors, we expect that in the province of Zeeland behavioral transmission between generations was less strong than in the other two provinces.

We also expect differences between social classes in the degree of transmission of ages at marriage over the generations. The more resources parents had, the better able and the more willing they were to manipulate the timing of their children's marriages. As property was the basis for status and political power, the upper class, the peasantry, and the petty bourgeoisie had a clear interest in and the opportunity to influence the age at marriage of their children (Mitterauer and Sieder 1982:134138). In the lower social classes, parents with no or little property were hardly able to delay a child's marriage since wage earning gave their offspring a certain degree of economic independence.

Finally, we assumed that there were differences in the degree of intergenerational transmission according to the sex of the child and according to the paternal versus the maternal line. Barber (2001) has argued that daughters are generally more strongly socialized by their mothers, and as a consequence might be more likely to look to their mothers as role models. Traditionally, in Western society, women have been more subject than men to parental control, particularly in the area of sexual behavior. Both factors would suggest that the strength of transmission would be greater among women than among men. On the other hand, in nineteenth-century society, the patriarchal principle was dominant, ensuring greater power, prestige, and influence for males. This would suggest that transmission via the paternal line was more likely than via the maternal line (see also Buss 1994). 


\section{Data and Variables}

We used data derived from marriage certificates that relate to all marriages contracted in the period 1812-1922 in three Dutch provinces: Zeeland in the southwestern part of the coastal zone, Limburg in the southeast, and Overijssel in the central eastern part of the country.

We have tried to link each marriage record to the marriage records of the parents and siblings of the bride and groom. This linkage was based on the combination of surnames and Christian names of both parents, as given in the child's and the parents' marriage certificates, allowing for small deviations. Both age at marriage and year of marriage of the child were used to reduce the number of pairs of parents that were eligible for linkage. The total number of marriages in the database was 574,000, of which 220,000 were in Overijssel, 190,000 in Limburg, and 164,000 in Zeeland. We were able to link $71.2 \%$ of these marriages to the marriage records of the parents. There is only a small change over time in the proportion of the total number of marriages represented by the individual provinces, with Overijssel showing a small increase and Zeeland a small decrease.

For the province of Limburg we found a substantially lower proportion of linked marriage records over the generations (52\%). In this province the Christian names of parents were sometimes only given as initials, in which case linkage was almost impossible. In addition, the dialect and the mixing of populations from Germany as well as from French-speaking Belgium had a negative effect on the linkage procedure because of spelling errors in foreign names and migration. Our final sample for Limburg is more selective than in the other provinces. It is possible that as a consequence we observed a higher or lower degree of transmission in the ages at marriage between generations here than was really the case.

In the analysis we use information from the marriage records on age at marriage, year of marriage, year of birth, social class, urban/rural character of the place in which the marriage occurred, and the number of married siblings. For each family we only know the number of married children that could be linked to their parents. Therefore, the number of married siblings used in the analysis is a proxy for the real number of married and unmarried siblings. Because this variable is highly skewed we truncate the number of married siblings in the final models at seven to prevent misspecification of the multilevel models. Multilevel models can be sensitive to highly skewed variables. In less than $4 \%$ of the families, the number of siblings is higher than seven. We therefore hardly lose any information by setting values of 8 and higher to 7 , whereas the estimates of the variance components become more stable.

Social class was determined on the basis of information about the occupation of grooms, as given on the marriage records. These historical occupational titles were classified into an abridged version of a social class scheme recently proposed by Van Leeuwen and Maas (2005), known as HISCLASS. We employ the following categories in our analyses: upper class, white-collar middle class, skilled workers, farmers, lower-skilled workers, unskilled workers, and farm workers. In the analysis, skilled workers serve as the reference category; all other categories are entered as dummy variables.

We constructed two analytic samples. It stands to reason that information on three generations backwards is most common for people marrying in the last part of the 
period studied and that this kind of information is not available for people marrying in the beginning of the registration period. Moreover, for the earliest part of the registration period, we are more likely to link children who married young to parents who married young as well. In other words, the chance of linking is higher for children whose parents married most recently (because old marriages are not in the registry). Since this could bias our analysis, we included two-generation marriages from 1840 onwards and three-generation marriages from 1860 onwards. In both samples, we excluded second and higher-order marriages (about 16\% of all marriages).

The two-generation sample is restricted to those brides and grooms for whom we have complete information on their own and their parents' age at marriage and on their own (i.e., the groom's) and their father's social class. Only marriages from families for which we have information on at least two siblings are included. This results in a final number of cases for the two-generation sample of 336,999 marriages in 102,704 families. The number of marriages is 111,957 in Zeeland, 149,921 in Overijssel, and 75,121 in Limburg.

The second analytic sample is restricted to those brides and grooms for whom we have information on three generations. We included all cases in which complete information was available about own age at marriage, parents' age at marriage, maternal and paternal grandparents' age at marriage, and groom's and father's social class. After selecting only marriages from families with information on at least two siblings, our three-generation sample includes 88,661 individuals (nested within 26,152 families). This is about $15 \%$ of the original data base. For various reasons mentioned earlier we found a lower number of intergenerational links in Limburg $(10,529$ marriages after final selection) than in the other two provinces $(37,763$ marriages in Zeeland and 40,369 in Overijssel).

\section{Methods}

Correlations between children's and parents' age at marriage give an indication of the strength of the intergenerational transmission. However, for a proper test of intergenerational transmission, we have to use multivariate multilevel models. The bivariate association between children's and parents' age at marriage could be partly spurious since there are other factors, such as social class, that parents and children have in common and that directly affect age at marriage of both the parents and their children. Standard multivariate regression models do not suffice in this case because they cannot deal with the unique information on multiple siblings per family. Multilevel models (Snijders and Bosker 1999) are particularly well suited to analyze this type of data. We use multilevel models that allow us to (a) estimate the total family effect on age at marriage and (b) obtain correct estimates for the effects of family characteristics on children's age at marriage.

Intergenerational transmission of age at marriage implies a positive correlation between siblings' age at marriage. After all, siblings whose parents married at a higher age would all be expected to marry relatively late, whereas siblings from parents who married at an early age should marry relatively young. In multilevel models, differences among families and differences among individuals are estimated 
simultaneously (Snijders and Bosker 1999). The model assesses how much of the total variation in age at marriage is attributable to the common family environment shared by married siblings and how much is attributable to factors unique to the individual siblings. The larger the family variance component relative to the individual component, the stronger the total family effect on age at marriage. An estimate of the correlation between siblings is obtained by dividing the family variance component by the total variance (Snijders and Bosker 1999:46). This estimate is called intraclass correlation and has two interpretations. First, it can be interpreted as the correlation between the ages at marriage of two randomly drawn siblings from one randomly drawn family. Second, it simply is the proportion of the total variance in age at marriage due to the family - in other words, indicating the size of the total family effect.

We estimate three models to test our hypotheses. Our first model includes an intercept and a linear effect of year of marriage. We add year of marriage because strong period effects could bias our estimates of the family effect. Nonlinear specifications of the period effect did not improve the model, nor did it affect the coefficients in the subsequent models. This first model estimates how much of the total variance in age at marriage is due to family differences and how much is due to individual characteristics. The intraclass coefficient shows us how important the family was for the age at marriage.

In the subsequent model, we add individual and family characteristics that determine age at marriage in order to take into account compositional differences between families (e.g., some families have sons only, and since, on average, males marry at an older age, this would make the family effect look bigger than it really is). The proportional reduction of the family variance component after adding these characteristics to the model tells us what part of the total family effect can be attributed to these family and individual factors.

In the final model, we enter parents' ages at marriage for the two-generation sample and parent's and grandparents' ages at marriage for the three-generation sample. This allows us to estimate which part of the family effect is brought about by intergenerational transmission. Parents' and grandparents' ages at marriage are specified as linear effects. The coefficients for parents' and grandparents' ages at marriage give a direct estimate of the magnitude of the intergenerational transmission. These coefficients can be interpreted as they would be in standard (ordinary least squares) regression models. See Sieben (2001) and Kalmijn et al (2006) for similar applications of multilevel models to assess family effects. In addition to parents' and grandparents' ages at marriage, model 3 includes a linear effect of the number of siblings and a linear effect of year of marriage. Rural place of marriage of the father and the groom and gender (male) are entered as simple dummy variables. Two sets of dummy variables are entered into the model for groom's social class and father's social class, respectively. In both cases, the category of skilled workers serves as the reference group.

Finally, we test our specific hypothesis by adding interaction effects to model 3. For instance, to test whether intergenerational transmission of age at marriage has become weaker we add two interaction effects; one for father's age at marriage and one for mother's age at marriage by year of marriage. We enter interaction effects separately for each specific hypothesis. 


\section{Results}

Table 1 and Fig. 1 give an overview of the characteristics of the two- and threegeneration samples. The average ages at marriage confirm that there were strong regional differences in age at marriage, with Limburg having the highest and Zeeland the lowest ages at marriage. On average, brides in Limburg were 2 years older when they married compared with brides from Zeeland.

\section{Correlations}

Table 2 gives us a first indication of the degree to which there was intergenerational transmission of age at marriage. This table shows the correlations between the ages at marriage of the various parties involved in the marriage: brides, grooms, their fathers and mothers, and the paternal and maternal grandparents. We observe significant and, at least for parents and children, quite substantial positive correlations. In Limburg, the correlation between ages at marriage is higher than in Overijssel and even more so than in Zeeland. Over time, the relation between ages at marriages has become stronger, a result that runs contrary to our expectations. A more detailed analysis, not shown here, makes it clear that the correlation between children's age at marriage and parents' age at marriage increased during the final two decades of the nineteenth century. In the last years of the observation period (after 1900), the increase seemed to stabilize.

\section{Multivariate Multilevel Regression Models}

Is there evidence for a family effect on age at marriage? We first answer this question by looking at the family variance components in Table 3. The baseline model (model 1) in Table 3 separates total variation in age at marriage into an

Table 1 Descriptive statistics for the three- and two-generation samples

\begin{tabular}{|c|c|c|c|c|c|c|c|c|}
\hline & \multicolumn{4}{|c|}{ Three-generation sample } & \multicolumn{4}{|c|}{ Two-generation sample } \\
\hline & Min & Max & $\%$ mean & SD & Min & Max & $\%$ mean & SD \\
\hline Male $(0=$ no, $1=$ yes $)$ & & & 47.5 & & & & 49.2 & \\
\hline Groom's age at marriage & 16 & 64 & 26.14 & 4.48 & 16 & 77 & 27.30 & 5.25 \\
\hline Bride's age at marriage & 15 & 60 & 24.14 & 4.03 & 15 & 77 & 24.99 & 4.60 \\
\hline Father's age at marriage & 16 & 60 & 25.99 & 4.20 & 16 & 70 & 26.91 & 4.83 \\
\hline Mother's age at marriage & 15 & 42 & 23.53 & 3.43 & 15 & 57 & 23.96 & 3.70 \\
\hline Father's father's age at marriage & 16 & 67 & 26.71 & 4.82 & & & & \\
\hline Father's mother's age at marriage & 15 & 48 & 24.05 & 3.94 & & & & \\
\hline Mother's father's age at marriage & 17 & 73 & 26.72 & 4.83 & & & & \\
\hline Mother's mother's age at marriage & 15 & 55 & 23.98 & 3.86 & & & & \\
\hline Year of marriage & 1860 & 1922 & 1904.80 & 12.86 & 1840 & 1922 & 1892.71 & 21.19 \\
\hline Birth year & 1826 & 1905 & 1879.67 & 12.99 & 1799 & 1906 & 1866.59 & 21.84 \\
\hline Groom rural place of marriage & & & 65.1 & & & & 64.2 & \\
\hline Father rural place of marriage & & & 71.9 & & & & 69.7 & \\
\hline Number of siblings & 2 & 19 & 4.41 & 2.06 & 2 & 20 & 4.41 & 2.05 \\
\hline$N$ of marriages & 88,661 & & & & 336,999 & & & \\
\hline$N$ of families & 26,152 & & & & 102,704 & & & \\
\hline
\end{tabular}



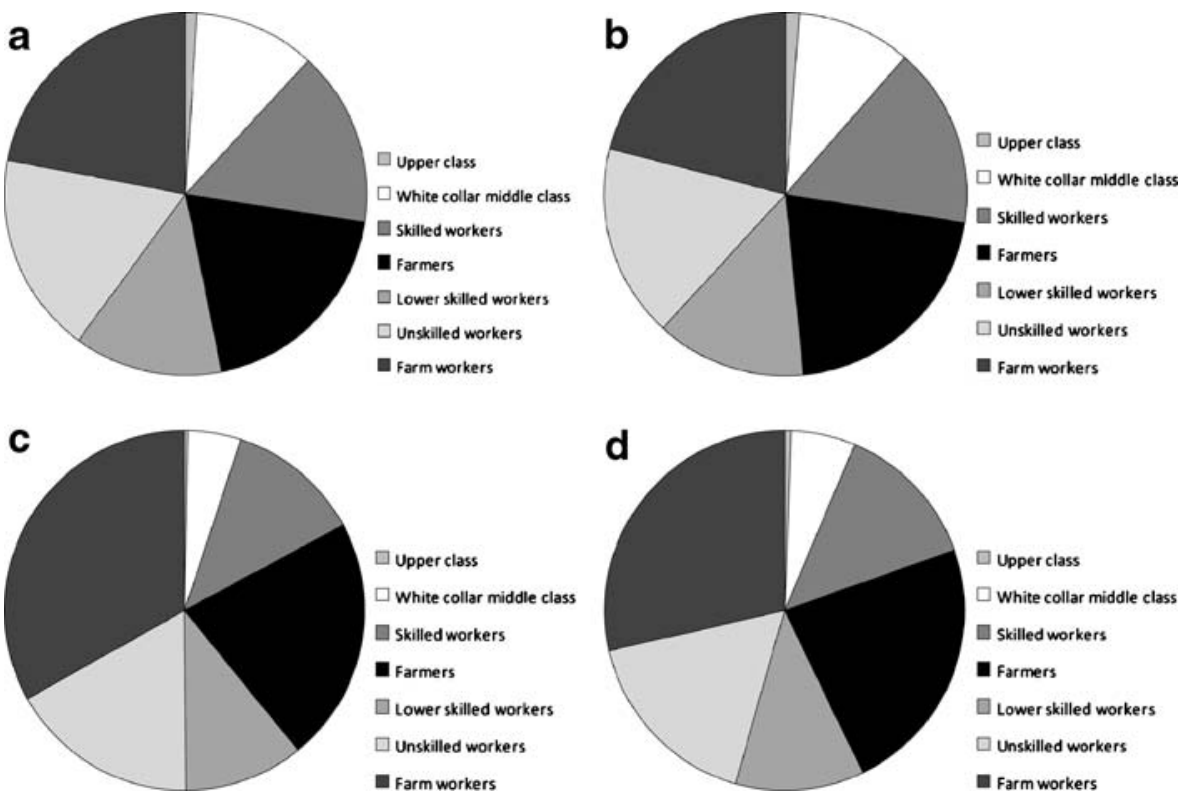

Fig. 1 Groom's and father's social class for the two- and three-generation samples. (a) Groom's social class, two-generation sample; (b) Groom's social class, three-generation sample; (c) Father's social class, two-generation sample; (d) Father's social class, three-generation sample

individual component and a family component. In our sample, $32 \%$ of the total variation can be attributed to family factors that married siblings have in common. This proportion can also be interpreted as the intraclass correlation coefficient. In other words, the estimated correlation between the ages at marriage of two randomly drawn siblings from a randomly drawn family is 0.324 . This indicates that there is a substantial family impact on age at marriage.

To what extent is the family effect on age at marriage caused by differences among families in sex composition, social class of the offspring, father's social class, and place of marriage? This question is answered by comparing model 2, in which we add individual and family characteristics, with the baseline model. The reduction of the family variance component when comparing model 1 with model 2 is $20 \%$. This means that a fifth of the total family effect on age at marriage is due to differences among families in sex composition, number of siblings, social class, and place of marriage.

Do parents' and grandparents' ages at marriage also contribute to the total family effect on age at marriage? In other words, are there effects of parents' age at marriage on their offspring's age at marriage, and can these effects explain part of the total family effect? To answer these questions father's and mother's ages at marriage are introduced in model 3 for the two-generation sample. The coefficients from this model are shown in Table 4. We observe that both father's and mother's ages at marriage have a significant positive effect on children's ages at marriage independent of other family effects. The reduction of variance at the family level increases from $20 \%$ to $27 \%$. The results for the three-generation sample are very similar. For this sample, we add parents' as well as grandparents' ages at marriage. 
Table 2 Correlations between age at marriage of (grand)parents and brides/grooms

\begin{tabular}{lll}
\hline & Bride & Groom \\
& & \\
\hline Three generations & & \\
Father & 0.153 & 0.216 \\
Mother & 0.181 & 0.185 \\
Father's father & 0.083 & 0.100 \\
Father's mother & 0.081 & 0.079 \\
Mother's father & 0.076 & 0.111 \\
Mother's mother & 0.071 & 0.083 \\
Two generations & & \\
Father & 0.150 & 0.200 \\
Mother & 0.167 & 0.167 \\
Zeeland & & 0.153 \\
Father & 0.112 & 0.109 \\
Mother & 0.116 & \\
Overijssel & & 0.197 \\
Father \\
Mother \\
Limburg \\
Father \\
Mother \\
1840-1869
\end{tabular}

The family effect is somewhat stronger in the three-generation sample. The four coefficients show that grandparents' ages have a positive and significant effect on their grandchildren's ages at marriage. Nevertheless, grandparents' ages at marriage hardly contribute to the reduction of the family variance component; there is about

Table 3 Variance components at the family and individual level from multilevel models regressing age at marriage on individual and family characteristics

\begin{tabular}{lccc}
\hline & Model 1 & Model 2 & Model 3 \\
\hline Two-generation sample & & & 5.9 \\
Family variance & 8.1 & 6.5 & 26.4 \\
\% reduction relative to Model 1 & & 19.8 & 15.8 \\
Individual variance & 16.8 & 0.289 & 0.272 \\
Intraclass correlation & 0.324 & 6.2 & 5.3 \\
Three-generation sample & & 17.9 & 29.8 \\
Family variance & 7.6 & 11.0 & 11.1 \\
\% reduction relative to Model 1 & & 0.362 & 0.325 \\
Individual variance & 11.6 & & \\
Intraclass correlation & 0.397 & & \\
\hline
\end{tabular}

Model $1=$ Year of marriage and province; model $2=$ model $1+$ individual variables (male, rural place of marriage, groom's social class) + family variables (father's social class, rural place of marriage, number of siblings); model 3 = model $2+$ parents' age at marriage + grandparents' age at marriage 
Table 4 Multilevel model regressing age at marriage on individual and family characteristics for the twoand three-generation samples

\begin{tabular}{|c|c|c|c|c|c|c|}
\hline & \multicolumn{3}{|c|}{ Two generations } & \multicolumn{3}{|c|}{ Three generations } \\
\hline & $b$ & SE & & $b$ & SE & \\
\hline \multicolumn{7}{|l|}{ Control variables } \\
\hline Overijssel (Zeeland = ref.) & 0.20 & 0.03 & & -0.15 & 0.05 & \\
\hline Limburg (Zeeland = ref.) & 1.67 & 0.03 & & 0.90 & 0.07 & \\
\hline \multicolumn{7}{|l|}{ Individual variables } \\
\hline Male & 2.14 & 0.02 & & 1.77 & 0.03 & \\
\hline Rural place of marriage & 0.18 & 0.03 & & -0.01 & 0.04 & ns \\
\hline \multicolumn{7}{|l|}{ Groom's social class* } \\
\hline Upper class & 1.16 & 0.08 & & 1.30 & 0.14 & \\
\hline White collar middle class & 0.64 & 0.03 & & 0.66 & 0.05 & \\
\hline \multicolumn{7}{|l|}{ Skilled workers (ref.) } \\
\hline Farmers & 1.06 & 0.03 & & 0.72 & 0.05 & \\
\hline Lower skilled workers & -0.53 & 0.03 & & -0.30 & 0.05 & \\
\hline Unskilled workers & -0.38 & 0.03 & & -0.35 & 0.05 & \\
\hline Farm workers & -0.51 & 0.03 & & -0.43 & 0.05 & \\
\hline \multicolumn{7}{|l|}{ Family variables } \\
\hline Father rural place of marriage & 0.74 & 0.03 & & 0.57 & 0.05 & \\
\hline Number of siblings & 0.00 & 0.01 & ns & 0.23 & 0.01 & \\
\hline \multicolumn{7}{|l|}{ Father's social class* } \\
\hline Upper class & 0.73 & 0.14 & & -0.16 & 0.32 & ns \\
\hline White collar middle class & -0.05 & 0.05 & ns & -0.18 & 0.10 & ns \\
\hline \multicolumn{7}{|l|}{ Skilled workers (ref.) } \\
\hline Farmers & 0.13 & 0.04 & & -0.32 & 0.07 & \\
\hline Lower skilled workers & -0.57 & 0.04 & & -0.56 & 0.08 & \\
\hline Unskilled workers & -0.80 & 0.04 & & -0.72 & 0.07 & \\
\hline Farm workers & -0.86 & 0.04 & & -0.75 & 0.07 & \\
\hline \multicolumn{7}{|l|}{ Family ages at marriage } \\
\hline Father & & & & 0.10 & 0.01 & \\
\hline Mother & & & & 0.17 & 0.01 & \\
\hline Paternal grandfather & & & & 0.02 & 0.00 & \\
\hline Paternal grandmother & & & & 0.02 & 0.01 & \\
\hline Maternal grandfather & & & & 0.02 & 0.00 & \\
\hline Maternal grandmother & & & & 0.01 & 0.01 & $* *$ \\
\hline
\end{tabular}

All coefficients are significant at the $p<0.01$ level unless indicated otherwise. Significance levels of a Wald-test are reported for the two sets of dummy variables for father's social class and groom's social class. The models also control for a linear effect of year of marriage

$b$ Unstandardized regression coefficient, $S E$ standard error, ref. reference category, $n s$ not significant ${ }^{*} p<0.001$ for both two and three generations; ${ }^{* *} p<0.05$

$1 \%$ extra reduction of the family variance component compared with a model that includes only parents' ages at marriage (results not shown).

What is the magnitude of the intergenerational transmission of age at marriage? The coefficients for parents' and grandparents' ages at marriage in Table 4 indicate the magnitude of the intergenerational transmission of age at marriage. In the threegeneration model, for instance, a 1-year increase in mother's age at marriage is associated with an increase of 0.17 years, or 2 months, in her child's age at marriage. To give an idea of how large the effects of parents' ages at marriage are, we can compare the effect of the ages of parents with the effect of social class. For example, the three-generation multivariate model shows that the average age of marriage is 0.72 years (almost 9 months) higher when the groom is a farmer than when the 
groom is a skilled worker. This is about a 5-year age difference in mother's age at marriage, which is associated with a 10-month increase in child's age at marriage $(5 \times 0.17$ years $=10$ months $)$. The effects of the grandparents' ages at marriage are five to eight times smaller than the effects of parents' ages at marriage. The magnitude of the total intergenerational transmission over three generations can be illustrated with a numerical example. If we take parents and grandparents into account, then the effect of all of them having married 5 years later than average is associated with their offspring marrying 1.7 years later than average.

In additional analyses not shown here, we estimated the total family effect for each province separately. In a model only including years of marriage and using the two-generation sample, the total family effect differs among the three provinces in the following way. In Zeeland, the intraclass coefficient is 0.28 , whereas it is 0.33 and 0.37 in Overijssel and Limburg, respectively. In the three-generation sample, we observe a similar ranking of the three provinces.

\section{Specific Hypotheses about Intergenerational Transmission}

Finally, in a series of additional models we test specific hypotheses by adding interaction effects to model 3. For reasons of presentation these models are not shown in the tables. Instead, we summarize the outcomes of the tests for these hypotheses.

First, we tested whether the effects of parents' ages at marriage decline over time. Contrary to our expectation, the interaction between marriage year and mother's age at marriage was significant and positive (unstandardized regression coefficient $b=$ $0.002, p<0.001)$. This suggests that the effect of mother's age increased over the studied period. Also, the interaction between father's age at marriage and year of marriage was significant and positive $(b=0.002, p<0.001)$. This means that the effect of father's age increased as well.

We also tested whether the effects of parental ages differed by sex of the child. Interaction effects between sex and parents' ages at marriage show that mother's age at marriage affected sons and daughters in the same degree $(b=0.000, p=0.99)$, whereas the effect of father's age at marriage was stronger for sons than for daughters $(b=0.07, p<0.001)$.

The final two interaction effects tested social class differences in intergenerational transmission of the age at marriage. We looked at father's social class only and found very little support for the hypothesis that intergenerational transmission was stronger among farmers than among other social classes. In fact, we found the opposite: intergenerational transmission of age at marriage was smaller among farmers than among other classes $(b=-0.027, p<0.001)$. We found no support for the hypothesis that intergenerational transmission was lower in the class of unskilled workers compared with all other classes $(b=-0.002, p<0.83)$. We found similar results for these interactions in the two-generation and three-generation samples.

\section{Conclusion and Discussion}

In this study, we examined to what extent there was intergenerational transmission of age at entry into marriage in three regions in the Netherlands in the late nineteenth 
and early twentieth centuries. Using a unique database, we found evidence of a clear family effect on age at marriage and substantial intergenerational transmission. In some families children tended to marry at younger ages, whereas children from other families married on average at older ages. The total impact that the family of origin had on age at entry into marriage can partly be attributed to social class and intergenerational transmission of age at marriage. Although its contribution to the total family effect was relatively small, the degree of intergenerational transmission was substantial. Children whose parents married at an older age were more likely to marry at an older age than children whose parents married at a younger age. We even observed positive effects of grandparents' ages at marriage on their offspring's age at marriage. Brides and grooms from a family in which parents and grandparents married 5 years later than average married 1.7 years later than average themselves.

We showed that intergenerational transmission of age at marriage is not a spurious association produced by social-class effects on age at marriage and the social reproduction of class positions. Some class effects on age at marriage in our data were opposite to our expectations: intergenerational transmission was weaker among farmers than among other social classes. As far as changes through time are concerned, our hypothesis was also not confirmed: it appeared that the effect of mother's age and of father's age actually increased over time. Especially during the last decades of the nineteenth century, there seems to have been an increase in the correlation between children's and parents' ages at marriage.

One might suggest that these remarkable results, concerning the role of time and social class, could be the result of our using a linkage procedure that might lead to biased estimates. We therefore ran our final model on a sample that included only marriages from 1900 to 1915 . We included marriage data only if they were available for two or more siblings in this period, and only if the bride or groom was 30 years of age or younger at the time of marriage. In this sub-sample, biases because of linkage problems are very unlikely. We obtained similar results to the ones for the bigger samples and, most important, the effects of parental age at marriage and the total family impact did not differ substantially from those in the bigger sample.

The fact that in the course of time no decrease in the degree of transmission took place while social classes with high levels of social control did not show higher levels of intergenerational transmission suggests that not social control but socialization was the main factor behind the transmission of behavior over the generations and that socialization became an increasingly important factor in the transmission process.

Substantial cultural components in the transmission of life course characteristics over the generations have been found in earlier studies, but to our knowledge, age at first marriage has hardly ever been included among these traits (except for Anderton et al. 1987). For social and cultural reasons, age at first reproduction was strongly affected by age at first marriage. The appropriate age to marry depended on the age at which individuals were not only physically but also economically and socially mature (Macfarlane 1986:211-216). This made age at first reproduction strongly dependent on cultural and social and economic factors as well. Kirk et al. (2001) argue that there may have been a real decrease in the selection gradient on age at first reproduction in the recent past thanks to improvements in diet and sanitation and the introduction of effective contraception. As a consequence, women can now reproduce more successfully at older ages and have greater control over their family 
size, and a relaxation of the selection on age at first reproduction is the result. Our study shows that in the pre-industrial and industrial populations that we compared there was hardly any change over time in the strength of transmission of a human life course characteristic that is strongly related to age at first reproduction.

Estimates of the heritability of life-history traits such as age at first reproduction for male human populations have seldom been made. Pettay et al. (2005) observed much higher heritability of female life course characteristics compared with male ones. Their expectation was that in monogamous study populations reproductive traits depended heavily on female qualities and were physiologically under female control. In our study the effect of father's age at marriage was indeed weaker than that of the mother's age, but male traits did show a high heritability as well. Pettay and colleagues identify economic resources and physical attributes, such as body height, as the male traits correlated with attractiveness to females that have a significant heritability in modern human populations. Our study indeed showed the importance of one of these attributes, social class, in linking ages at marriage over the generations but at the same time made clear that other factors play a role as well.

To identify what factors in the socialization process were the most important ones, more detailed data on family circumstances are needed: for example, the religious background of the couple and their income. Information on these characteristics will in the near future become available in historical projects currently underway. Adding these presently unmeasured family factors will probably explain a major part of the total family effect.

Acknowledgments Constructive comments by three anonymous referees are gratefully acknowledged. Marco van Leeuwen (International Institute for Social History, Amsterdam) placed HISCLASS's basic coding list at our disposal. We wish to thank the Zeeuws Archives, the State Archives of Limburg (Rijksarchief Limburg), and the Historic Centre Overijssel for placing their data at our disposal.

\section{References}

Alter, G., \& Oris, M. (1999). Access to marriage in the East Ardennes during the 19th century. In I. Devos, \& L. Kennedy (Eds.) Marriage and rural economy: Western Europe since 1400 (pp. 133-151). Turnhout: Brepols.

Anderton, D. L., Tsuya, N., Bean, L., \& Mineau, G. (1987). Intergenerational transmission of relative fertility and life course patterns. Demography, 24, 467-480.

Ariès, P. (1982). Two successive motivations for the declining birth rate in the West. In C. Höhn, \& R. Mackensen (Eds.) Determinants of fertility trends (pp. 123-130). Liège: Ordina Editions.

Axinn, W. G., \& Thornton, A. (1992). The influence of parental resources on the timing of the transition to marriage. Social Science Research, 21, 261-285.

Barber, J. (2001). The intergenerational transmission of age at first birth among married and unmarried men and women. Social Science Research, 30, 219-247.

Buss, D. M. (1994). The evolution of desire: Strategies of human mating. New York: Basic Books.

De Haan, H. J., \& Hoppenbrouwers, P. C. M. (1994). Intergenerational transfer of rural property in the Netherlands: Law, moral code and practice (16th-20th centuries). Paper presented at the Eleventh Economic History Congress (Section C33), Milan.

Flinn, M. W. (1981). The European demographic system, 1500-1820. Brighton: Harvester Press.

Glass, J., Bengtson, V. L., \& Dunham, C. C. (1986). Attitude similarity in three-generation families: Socialization, status inheritance, or reciprocal influence. American Sociological Review, 51, 685-698.

Goode, W. J. (1963). World revolution and family patterns. New York: Free Press of Glencoe.

Hogan, D. P., \& Astone, N. M. (1986). The transition to adulthood. Annual Review of Sociology, 12, 109-130.

Kalmijn, M., Liefbroer, A., van Poppel, F., \& van Solinge, H. (2006). The family factor in Jewish-Gentile intermarriage: A sibling analysis of the Netherlands. Social Forces, 84, 1347-1358.

Springer 
Kirk, K. M., Blomberg, S. P., Duffy, D. L., Heath, A. C., Owens, I. P. F., \& Martin, N. G. (2001). Natural selection and quantitative genetics of life-history traits in Western women: A twin study. Evolution, 55, 423-435.

Kohler, H.-P., Rodgers, J. L., \& Christensen, K. (1999). Is fertility behavior in our genes? Findings from a Danish twin study. Population and Development Review, 25, 253-288.

Levine, D. (1982). "For their own reasons": Individual marriage decisions and family life. Journal of Family History, 6, 255-264.

Macfarlane, A. (1986). Marriage and love in England: Modes of reproduction, 1300-1840. Oxford: Basil Blackwell.

Mason, K. O. (1993). The impact of women's position on demographic change during the course of development. In N. Federici, K. O. Mason, \& S. Sogner (Eds.) Women's position and demographic change (pp. 19-42). Oxford: Clarendon.

Mitterauer, M., \& Sieder, R. (1982). The European family. Chicago: University of Chicago Press.

Modell, J., Furstenberg, F., \& Hershberg, T. (1976). Social change and transitions to adulthood in historical perspective. Journal of Family History, 1, 7-33.

Murphy, M. (1999). Is the relationship between fertility of parents and children really weak. Social Biology, 46, 122-145.

Murphy, M., \& Wang, D. (2002). The impact of intergenerationally-transmitted fertility and nuptiality on population dynamics in contemporary populations. In J. Rodgers, \& H-P. Kohler (Eds.) Biodemography of human reproduction and fertility (pp. 209-228). Boston: Kluwer Academic.

Pettay, J. E., Kruuk, L. E. B., Jokela, J., \& Lummaa, V. (2005). Heritability and genetic constraints of lifehistory trait evolution in preindustrial humans. PNAS, 102, 2838-2843.

Reher, D. (1998). Family ties in Western Europe: persistent contrasts. Population and Development Review, 24, 203-234.

Shorter, E. (1977). The making of the modern family. Glasgow: Fontana.

Sieben, I. (2001). Sibling similarities and social stratification: The impact of family background across countries and cohorts. Amsterdam: Thela Thesis.

Snijders, T., \& Bosker, R. J. (1999). Multilevel analysis. An introduction to basic and advanced multilevel modeling. London: Sage.

Van Leeuwen, M. H. D., \& Maas, I. (2005). A Historical international social class scheme for occupational titles in the past. Paper presented at the XVIth International Conference of the Association for History and Computing, Amsterdam, The Netherlands, 14-17th September 2005.

Wichers, A. J. (1965). De oude plattelandsbeschaving: Een sociologische bewustwording van de 'overherigheid'. Assen: Van Gorcum/Prakke.

Wrigley, E. A., Davies, R. S., Oeppen, J. E., \& Schofield, R. S. (1997). English population history from family reconstitution 1580-1837. Cambridge: Cambridge University Press.

Frans van Poppel, Ph.D. is senior researcher at the Netherlands Interdisciplinary Demographic Institute of the Royal Academy of Sciences in The Hague, Netherlands. His research focuses on the history of public health, marriage and family formation. Recent publications include van Poppel, F., Jonker, M., \& Mandemakers, K. (2005). Differential Infant and Child Mortality in three Dutch Regions, 1812-1909. Economic History Review, 58(2), 272-309; Derosas, R., \& van Poppel, F. (Eds.) (2006). Religion and the Decline of Fertility in the Western World. Dordrecht: Springer; Woods, R. I., Løkke, A., \& van Poppel, F. (2006). Two Hundred Years of Evidence-based Perinatal Care: Late-Fetal Mortality in the Past. Archives of Disease in Childhood - Fetal and Neonatal Edition, 91, 445-447.

Christiaan Monden, Ph.D. is assistant professor in the Department of Sociology, Tilburg University. His research is grouped around three themes: (1) socioeconomic inequalities in health, (2) the effects partners have on each other's health and (3) the health effects of and on demographic and socioeconomic transitions during the life course (e.g. divorce). Related publications: Kalmijn, M., \& Monden C. W. S. (2006). Are the effects of divorce on well-being dependent on marital quality? Journal of Marriage and Family, 68(5), 1197-1213; Monden, C. W. S., \& Smits, J. (2005). Ethnic intermarriage in times of social change: The case of Latvia. Demography, 42(2), 323-345. 
Kees Mandemakers, Ph.D. is senior researcher and head of the Historical Sample of the Netherlands (HSN) at the International Institute for Social History (IISH) in Amsterdam. His main research interest are the methodology of large historical databases, social stratification and mobility, and educational history. Recent publications: Mandemakers, K., \& Dillon, L. (2004). Best practices with large databases on historical populations. Historical Methods, 37(1), 34-38; Kok, J., Mandemakers, K., \& Wals, H. (2005). City nomads: Changing Residence as a Coping Strategy, Amsterdam, 1890-1940. Social Science History, $29(1), 15-44$. 